\title{
ESEF 70 Anos: o processo de federalização sob o olhar discente
}

\author{
Silvana Vilodre Goellner* \\ Johanna Coelho Von Mühlen** \\ André Luis dos Santos Silva*** \\ Luciane Silveira Soares**** \\ Marco Antonio Ávila de Carvalho*****
}

\begin{abstract}
Resumo: Este artigo analisa o processo de federalização da Escola de Educação Física da Universidade Federal do Rio Grande do Sul sob o olhar dos discentes que se graduaram em 1970 na primeira turma formada sob o regime federal de ensino. Fundamentada no aporte teórico da História Cultural analisamos aspectos relacionados ao envolvimento político dos alunos nesse processo bem como aspectos relacionados a estrutura e funcionamento da Escola como um todo. Para tanto, recorremos a História Oral entrevistando discentes e docentes do período bem como analisamos fontes de diversa natureza tais como documentos, atas de reuniões, livros, reportagens de jornal, fotografia entre outras. Da análise realizada apreendemos que esta turma vivenciou a federalização de modo muito peculiar: por dentro do processo, mas, em certa medida, muito afastada dele.
\end{abstract}

Palavras-chave: Historia do século XX: Brasil. Política. Educação física. Estudantes. Universidades.

\footnotetext{
*Licenciada em Educação Física. Mestre em Ciências do Movimento Humano. Doutora em Educação. Professora na graduação e pós-graduação da Escola de Educação Física da UFRGS. Coordenadora do Centro de Memória do Esporte da ESEF/UFRGS (CEME) e do Grupo de Estudos sobre Cultura e Corpo. (GRECCO). Porto Alegre, RS, Brasil. E-mail: vilodre@gmail.com **Licenciada em Educação Física. Especialista em Pedagogias do Corpo e da Saúde. Mestre e Doutoranda em Ciências do Movimento Humano. Membro do GRECCO e do CEME. Porto Alegre, RS. E-mail: johanna.coelho@hotmail.com

***Doutorando em Ciências do Movimento Humano na UFRGS. Docente dos cursos de Educação Física e Pedagogia na Universidade FEEVALE. Porto Alegre, RS, Brasil. E-mail: andrels@feevale.br

****Bacharel em Bilbioteconomia. Especialista em Arte, Corpo e Educação. Mestranda do PPGCMH/ESEF/UFRGS. Membro do GRECCO e do CEME. Porto Alegre, RS. Porto Alegre, RS, Brasil. E-mail: luzbib@gmail.com

*****Licenciado em Educaçao Física. Membro dos grupos de estudos GRECCO e CEME. Porto Alegre, RS, Brasil. E-mail: marco.esef@gmail.com>
} 


\section{INTRODUÇão}

A Escola Superior de Educação Física do Estado do Rio Grande do Sul (ESEF), completou, no ano de 2010, setenta anos de existência. Pioneira na formação superior dos educadores físicos no Estado, a ESEF, ao longo de sua trajetória, possui passagens diversas e interessantes, como suas reivindicações por instalações próprias e adequadas (MAZO, 2005), o afastamento do diretor da Escola por oposição do Diretório Acadêmico (KAMINSKI; GOELLNER, 2010), os momentos sobre tutela do Estado (MAZO, 2005; KAMINSKI; GOELLNER, 2010) e o processo de federalização (NUNES; MOLINA NETO, 2005). Ao longo desses setenta anos as histórias da ESEF multiplicam-se e as possibilidades de contá-las, são muitas.

Fundamentada no aporte teórico-metodológico da História Cultural e História Oral esta pesquisa tematiza o processo de federalização da ESEF sob o olhar dos discentes que se graduaram em $1970^{1}$. O critério para a escolha desta turma específica justificase por ser a primeira a concluir a graduação com a Escola já federalizada. Ou seja, seus integrantes vivenciaram de modo particular as alterações que aconteceram no seu cotidiano em função dessa importante alteração na sua administração.

Para tanto, recorremos a fontes de diferente natureza tais como atas e documentos oficiais da Escola, reportagens publicadas em jornais locais, artigos já produzidos sobre a ESEF e, fundamentalmente, entrevista com seis ex-alunos dessa turma ${ }^{2}$ além de outras entrevistas realizadas anteriormente e que compõem o acervo documental do Centro de Memória do Esporte da ESEF/

\footnotetext{
${ }^{1}$ A cerimônia de formatura da turma aconteceu no dia 22 de dezembro de 1970. Conforme o convite de formatura, nesse dia, graduaram-se 26 professores e 41 professoras.

${ }^{2} E$ importante registrar que os alunos e alunas integrantes dessa turma realizam encontros periódicos nos quais se reúnem para manter vínculos e rememorar sua passagem pela ESEF. No ano de 2010, celebraram seus 40 anos de formatura e, dentre as atividades desenvolvidas, realizaram uma visita a Escola contando, inclusive, com a presença de três de seus professores. Ocasião na qual foi possível realizar um primeiro contato com os entrevistados bem como solicitar a doação, ao Centro de Memória do Esporte, de materiais diversos objetivando compor o acervo relativo à própria ESEF.
} 
UFRGS $^{3}$ (CEME). A concepção de história que orienta essa pesquisa (FALCON, 2002; PESAVENTO, 2003) parte do entendimento de que os depoimentos desses ex-alunos não representam a verdade, mas o modo como perceberam o processo de federalização da ESEF, o que constitui uma possível versão daquela história. Suas falas, reticências, e silêncios gravados e transcritos no processo de tessitura desse texto, traduz uma possível versão, uma das muitas possibilidades de se constituir a narrativa daqueles acontecimentos. Nas trilhas da história Oral, entendemos que o depoimento sobre o passado é permeado por outras lembranças, esquecimentos, é atravessado pelo tempo presente. Acessar as memórias, sentimentos e significados do que foi o processo de federalização da ESEF, diz respeito à "presença do passado no presente imediato das pessoas" (MEIHY, 1998, p.13), portanto, impossível de ser contada como de fato aconteceu.

Para além da veracidade do narrado, entendemos que esses depoimentos revelam-se, ainda, como fontes produzidas para novos estudos visto que a História Oral é aqui assumida como um método, uma técnica e também uma fonte de pesquisa (ALBERTI, 1989; FERREIRA; AMADO, 1996) pois:

[...] privilegia a realização de entrevistas com pessoas que participaram de, ou testemunharam, acontecimentos, conjunturas, visões de mundo, como forma de se aproximar deste objeto de estudo. Como consequiência, o método de história oral produz fontes de consulta (entrevistas) para outros estudos, podendo ser reunidas em um acervo aberto a pesquisadores. Trata-se de estudar acontecimentos históricos, instituições, grupos sociais, categorias profissionais, etc., à luz de depoimentos de pessoas que deles participaram ou os testemunharam. (ALBERTI, 1989, p. 1-2)

\footnotetext{
${ }^{3} \mathrm{O}$ CEME desenvolve, desde 2002, o projeto Garimpando Memórias cujo foco está direcionado para a realização de entrevistas e seu processamento de modo a constituírem como fontes de pesquisa. As entrevistas referidas encontram-se no acervo Memórias da ESEF e podem ser consultadas, na integra, em http://www.esef.ufrgs.br/ceme/projetos/garimpando/entrevistas/ esef/esef.html.
} 
Reconstruir histórias é, também, reconstruir memórias, isto é, experiências individuais e coletivas, pois, ainda que a memória seja guardada por um indivíduo e tem como referência suas experiências e vivências, essa memória está marcada pelo grupo social onde conviveu e se socializou. É exatamente esse caráter social aquilo que se constitui como elemento essencial da formação de sua identidade, da percepção que tem de si mesmo e dos outros (ROUSSO,1996).

Assim como a entrevista está intimamente relacionada à memória, seu processamento articula, simultaneamente, pesquisa e documentação visto que possibilita, também, a produção de um documento histórico. Daí sua riqueza, pois, "a evidência oral, transformando os "objetos" de estudo em "sujeitos", contribui para uma história que não só é mais rica, mais viva e mais comovente, mas também mais verdadeira" (THOMPSON, 1992, p. 136). Não no sentido de que o que está sendo relatado efetivamente aconteceu, mas de que há ali uma vida a ser exposta a partir de quem a viveu. Nesse sentido, as entrevistas foram produzidas e processadas contemplando os seguintes procedimentos metodológicos: a) Identificação das pessoas a serem contatadas para as entrevistas; b) Elaboração de roteiros para cada; c) Realização da entrevista com gravação digital; d) Processamento da entrevista - transcrição, conferência de fidelidade, copidesque e leitura final; e) Devolução da entrevista na linguagem escrita para conferência do entrevistado; f) Assinatura, por parte do entrevistado, de um documento concedendo ao Centro de Memória do Esporte do Esporte da Escola de Educação Física a propriedade e os direitos de divulgação do depoimento de caráter histórico e documental ${ }^{4}$.

Do diálogo das entrevistas com as outras fontes documentais foi possível construir as análises que se seguem que podem ser

\footnotetext{
${ }^{4}$ Esses procedimentos fundamentam o projeto "Garimpando Memórias: esporte, lazer, dança e educação física". A pesquisa em tela integra esse projeto e foi aprovada pelo Comitê de Ética da UFRGS através parecer de número 2007710.
} 
condensadas em dois grandes temas: a des(politização) discente e sua percepção diante da nova ESEF que emergia frente a federalização.

\section{A Escola Superior de Educação Física no contexto da Federalização}

O ano de 1940 marca a data de criação da ESEF. Naquele momento, a Educação Física era valorizada como meio de formar cidadãos brasileiros e solidificar a campanha em prol do nacionalismo. A constituição brasileira de 1937 estabelecia a obrigatoriedade da Educação Física nas escolas primárias, secundárias e normais, o que demandava maior número de profissionais qualificados. Para além disso, o decreto 1.212 de 1939 exigia formação específica para professor de Educação Física, técnico esportivo e Médico especializado em Educação Física e Esportes (NEGRINI, 1996). A Educação Física por volta da década de 1930 fazia parte de um projeto nacionalista, de construção identitária nacional apregoada pelo Estado Novo (CASTELLANI FILHO, 1988; FERREIRA NETO, 1999; MAZO, 2005)

A ESEF surge, em meio a uma agitação política que identificava a Educação Física como capaz de conferir educação moral e física aos brasileiros. Sua criação ficou a cargo do Departamento de Educação Física do Estado do Rio Grande do Sul (DEEF), órgão técnico subordinado à Secretaria de Educação do Estado, fundando em 1939 com o objetivo atender as exigências de formação especializada em Educação Física.

Suas atividades iniciaram através de parcerias com diversos clubes e associações da cidade de Porto Alegre visto que, nesse momento, a ESEF ainda não possuía instalações próprias para o seu pleno funcionamento (GUTIERREZ, 1971). Além disso, o Estado, seu provedor, tinha dificuldades em fornecer as condições materiais objetivas necessárias ao seu pleno funcionamento, o que representava um "peso" para o orçamento do governo (NUNES; MOLINA NETO, 2005). Tão somente na década de 1960 a ESEF recebeu um 
terreno no qual poderia centralizar suas ações. Por meio de algumas mobilizações discentes, a sua sede, antes localizada na Associação Cristã de Moços (ACM), foi transferida, entretanto, naquele novo espaço não havia instalações apropriadas e a parceria com entidades esportivas ainda se fazia necessária (CARVALHO, 2010). Para dar segmento às atividades, professores, funcionários e alunos trabalharam juntos para que, gradativamente, a nova sede estivesse em condições de ser utilizada (CASSEL, 2005).

Em outro momento, na década de 1950, o então Reitor Alexandre Rosa, sugeriu a construção de instalações destinadas à ESEF junto ao hospital de Clinicas da UFRGS. Neste momento a URGS, mantida pelo Estado do Rio Grande do Sul já havia sido federalizada, dando origem à Universidade Federal do Rio Grande do Sul(UFRGS). Entretanto a falta de recursos do estado inviabilizou o projeto que poderia ter federalizado a ESEF, já na década de 1950 (NUNES; MOLINA NETO, 2005).

Foi então, somente em 16 de setembro de 1970, que foram assinados os atos formais do processo de federalização. Segundo Gutierrez (1971, p. 2).,

[...] a federalização vem a surgir pelo Decreto $n^{\circ}$ 997, de 21 de outubro de 1969, assinado pelos três Ministros Militares no exercício da Presidência, sendo Ministro da Educação o Deputado Tarso Dutra. Em 16 de setembro de 1970, em emocionante histórica cerimônia no Ginásio de Esporte, com a presença do Ministro de Educação - Prof. Cel. Jarbas Passarinho, do governador do Estado - Cel. Walter Perachi de Barcelos, do Secretário da Educação e Cultura - Dr. Luiz Lesseigneur de Farias, do Magnífico Reitor da UFRGS - Prof. Eduardo Z. Faraco e de outras altas autoridades, foram assinados os atos finais da passagem da ESEF do âmbito Estadual para o Federal.

Neste período ainda foram criados o Centro Olímpico, órgão cujo objetivo era gerir o desporto universitário da UFRGS e, posteriormente, o Laboratório de Pesquisa do Exercício com o intuito de melhorar o desempenho esportivo dos atletas brasileiros 
(CARVALHO, 2010). Diante do contexto histórico vivido no país, no qual há a ascensão do fenômeno esportivo ${ }^{5}$, a ESEF começa a construir sua estrutura para dar condições à formação dos professores de Educação Física e suprir as demandas exigidas pela Lei de Diretrizes e Bases (LDB) de 1961, que fixa a obrigatoriedade da Educação Física nos ensinos primário e secundário, e da Reforma Universitária de 1968, que torna obrigatória a prática da Educação Física, também, no ensino superior (NUNES; MOLINA NETO, 2005). Tais iniciativas governamentais, ao mesmo tempo que impulsionaram a ESEF como instituição de ensino possibilitaram, provocaram, também, tensões a partir de diferentes entendimentos dos sujeitos que constituem sua comunidade: militares, médicos, professores, estudantes e servidores, inclusive no que respeita a sua federalização. A turma graduada em 1970 é aqui tomada como uma das múltiplas formas de entender esse processo pois a viveu de perto o que não significa que dele tenha participado efetivamente.

\section{A(DES)Polmização de QUEM VIVEU A FEDERALIZAÇÃo POR DENTRO}

[...] naquela época, quem era atinado, estava fazendo um movimento político. Quem não era, estava fazendo o seu curso lá bem desligado do mundo. [...] Algumas pessoas individualmente eram mais antenadas e sabiam o que estava acontecendo, o que estava passando. (OLIVEIRA; FERREIRA; KROEFF, 2010, p. 21).

O Diretório Acadêmico dos Estudantes de Educação Física foi organizado no ano de 1941, um ano após a criação da ESEF. Essa entidade representativa foi reorganizada em 1957, momento em que os estudantes receberam um espaço para sediar a entidade. Com reuniões regulares, um novo estatuto e circulação do "Olímpico", jornal organizado e publicado por iniciativa do Diretório Acadêmico, a representação discente vivia uma nova fase, mais fortalecida e organizada. Talvez, isso tenha acontecido em decorrência de

\footnotetext{
${ }^{5}$ Neste mesmo período há um incentivo às práticas esportivas ligadas à Educação Física, por parte do governo federal. Neste sentido podemos destacar os Jogos Universitários Brasileiros e os Jogos Escolares Brasileiros (OLIVEIRA, 2003).
} 
mudanças estruturais sofridas pela ESEF, as quais dizem respeito a: incremento de um ano no processo de formação dos estudantes de Educação Física ${ }^{6}$ e a obrigatoriedade dos candidatos ao curso possuírem o ensino secundário completo. Essas mudanças foram introduzidas pelo Ministério da Educação, justamente no ano de reorganização do Diretório, em 1957. Assim sendo, um ano a mais de curso e a exigência de alunos mais "maduros" possibilitou uma nova gestão estudantil que passou a tensionar a então direção da escola (KAMINSKI; GOELLNER, 2010).

Em 1958, um movimento reivindicatório originado pelos estudantes demanda ao diretor Frederico Guilherme Gaelzer ${ }^{7}$ e ao Conselho Técnico Administrativo uma série de exigências, dentre as quais: horários para reuniões e assembleias dos estudantes; participação de representante discente nas reuniões do Conselho Técnico Administrativo; repasse de verbas pertencentes ao Diretório Acadêmico, questões referentes à frequência, faltas, presenças, atestados médicos entre outras, culminando com o afastamento do então diretor no ano de $1959^{8}$.

Alguns anos mais tarde o contexto político brasileiro dá sinais de crise em decorrência da política econômica adotada pelo governo João Goulart. O resultado foi uma forte pressão por parte de vários setores sociais que resultou no golpe de Estado que deu origem a Ditadura Militar, em 1964. Nos dias seguintes ao "Golpe", os estudantes de Educação Física da ESEF encontraram o Diretório Acadêmico. arrombado e saqueado. Em decorrência disso, foi aberta uma sindicância cujos integrantes, de algum modo, estavam ligados ao serviço militar. Os membros do movimento estudantil da ESEF foram responsabilizados pelo ato de vandalismo e após essa data, o Diretório passou a ser presidido pelos próprios estudantes militares que averiguaram o ato (KAMINSKI; GOELLNER, 2010).

${ }^{6} \mathrm{O}$ curso que era concluído com dois anos de estudos passou a exigir três anos.

${ }^{7}$ Diretor da ESEF de 1955 a 1959.

${ }^{8}$ Não se pode afirmar que seu o afastamento foi em função da pressão dos estudantes, sobretudo porque, segundo os documentos, o período de permanência de Frederico Gaelzer, na direção da escola, já estava por terminar. (KAMINSKI; GOELLNER, 2010) 
Durante o período regido pela Ditadura Militar houve um enfraquecimento da ação estudantil em virtude do rigor e da repressão. Isso se verifica tanto no âmbito local da ESEF quanto nacional. A União Nacional dos Estudantes de Educação Física (UNEEF) ${ }^{9}$, assim como outras entidades de organização estudantil foram duramente perseguidas. Apesar disso, no ano de 1967, em São Paulo, ocorreu mais um encontro nacional da UNEEF (KAMINSKI; GOELLNER, 2010).

É justamente nesse contexto que a ESEF foi federalizada. Segundo Bemvenuti (2010), membro do Diretório Acadêmico da época, posicionar-se politicamente não era tarefa fácil:

Eu estava a par de tudo. Os outros não participavam muito. Politicamente, a turma da época, era mais alienada do que qualquer outra coisa. Era difícil de lidar. Eu me lembro que a maioria queria que eu fechasse com a turma da direita. Eram poucos que chegavam e diziam: "Não...". Mas como o peso já não era tão ideológico e sim de se concretizar a proposta nós ficamos (BEMVENUTI, 2010, p. 16).

Se é possível conceber que assumir um posicionamento político na época era difícil, em face à repressão e as atitudes truculentas para com os estudantes, no caso do Diretório Acadêmico isso se complicava ainda mais. Segundo o depoimento de Bemvenuti, não se tratava apenas de ser de direita ou esquerda: significava transitar ora por uma vertente política, ora por outra, uma vez que havia grande vontade por parte de alunos e funcionários para que a ESEF fosse federalizada. Naquele momento, assumir um posicionamento claro e dar visibilidade a ele poderia significar a não concretização do processo de federalização.

E era pesado naquele tempo tu teres uma decisão de ser de esquerda. Isso significava ter um carimbo pelo resto da vida. Eu já vinha de política estudantil

\footnotetext{
${ }^{9}$ Fundada em decorrência do congresso da União dos Estudantes em 1956, em Nova Friburgo, Rio de Janeiro. (SILVA, 2010)
} 
lá do secundário, já tinha certo conhecimento. Participei em 1964, contra, é lógico, mas não adiantou (BEMVENUTI, 2010, p. 16).

A tensão quanto à possibilidade de não federalizar estava posta naquele momento, talvez, por tentativas anteriores frustradas. Durante as reuniões do Conselho Universitário (CONSUN), entre 1966 e 1968, muito se discutiu sobre a incorporação da ESEF à UFRGS. No dia 22 de fevereiro de 1968, um pequeno grupo de professores da ESEF manifestou-se em prol de sua incorporação à UFRGS. Em votação, o CONSUN não acatou a proposta de incorporação e o processo de federalização, naquele momento, foi vetado.

É importante pensar que as reuniões do CONSUN atendiam às exigências do Conselho Federal de Educação voltadas à adaptação das Universidades às mudanças decorrentes da Reforma Universitária, implantada pela lei 5540/68. Apesar de datar de fins da década de 1960, o processo de Reforma, há tempos, se estabelecia.

A partir da década de 1950 o Brasil firmou vários acordos com os Estados Unidos que dariam base, mais tarde, para a reforma estrutural da universidade brasileira. Manifestações contrárias partiram dos estudantes. A UNE, mesmo na clandestinidade, devido à instauração do modelo político ditatorial, em 1964, protestava contra os acordos MEC-USAID (United States Agency for International Development). Em meio a esse contexto turbulento, o processo de federalização da ESEF se depara com vias de novas investidas, o que exigiria bastante cuidado por parte dos diferentes segmentos da ESEF, em especial, aqueles envolvidos com o processo.

Eu nunca me esqueço que assim que eu assumi [o Diretório Acadêmico] o diretor [Fredolino Taube ${ }^{10}$ ] me chamou no gabinete dele: "Olha, tu cuida porque vai agora dar a Federalização. Tu cuida o que tu falas, o que fazes, tu cuida para que lado tu tende, porque disso depende a federalização. Se sair por aí

${ }^{10}$ Fredolino Adalberto Ricardo Taube (1970-1971) 
dizendo que tu és de esquerda, fechou. Não tem mais a Federalização, porque os caras não vão federalizar uma Escola no qual o Diretório Acadêmico é da esquerda". Ele era muito preocupado com isso. [...]. De repente, assim como eles assinaram para federalizar, eles poderiam cancelar a assinatura e dizer que não ia mais federalizar e pronto. Nós tínhamos essa preocupação. (BEMVENUTI, 2010, p. 16)

O professor Taube assumiu a direção da ESEF em no ano de 1970, em substituição ao diretor Hélio Ferreira que se afastou antes de serem realizadas novas eleições para o cargo. Neste momento, o decreto 997 de 21 de outubro de 1969 já havia sido assinado e a ESEF já havia sido incorporada à UFRGS (NEGRINI, 1996), entretanto, como um decreto que poderia ser revogado ${ }^{11}$. A oficialização do processo ainda não havia se estabelecido. Ainda havia coisas a fazer, ainda era necessário cautela. Segundo Nunes e Molina Neto (2005) é possível pensar que a figura de Fredolino Taube não seria escolhido para direção da escola, naquele momento, aleatoriamente. Como dito, não houve eleição para o cargo e o nome do novo diretor foi decidido por funcionários da Secretaria Estadual de Educação que ainda era o órgão que mantinha a ESEF. Segundo o próprio professor Taube, a ESEF é considerada um "peso" para o Estado do Rio Grande do Sul que tinha dificuldades em dar-lhe suporte. Neste sentido, havia um grande interesse também por parte dos órgãos estatais em concluir o processo de federalização ${ }^{12}$ e $o$ fato de Taube ser nomeado como diretor indica que suas posições políticas auxiliariam para que a incorporação da ESEF à UFRGS se concretizasse.

\footnotetext{
${ }^{11}$ Esse decreto beneficiou não só a ESEF, mas também a Escola de Educação Física de Minas Gerais e a Escola de Serviço Social de Natal. Assim essas instituições de ensino superior foram federalizadas nesse mesmo período (MAZO, 2005). No diz respeito à incorporação das escolas de Educação Física, é importante salientar que havia grande interesse do Governo Federal em capacitar maior número de professores para suprir suas exigências ideológicas (NUNES; MOLINA NETO, 2005).

${ }^{12}$ Havia uma série de exigências para que a federalização se efetivasse e o estado do Rio Grande do Sul se empenhava para se provê-las. Muitas dessas exigências dizia respeito a condições materiais. Segundo Carmo, citada por Nunes e Molina Neto (2005, p.181): "[...] a UFRGS não queria só as pessoas, tinha que ter um bem comum, que eles pudessem ter segurança".
} 
Ao longo do depoimento de Bemvenuti é possível identificar alguns detalhes sobre o processo da federalização, pois, em função de liderança no Diretório Acadêmico, circulava de modo frequente na Reitoria e em outros espaços de decisão política.

[...] o que eles queriam saber - isso que é interessante - qual a tendência política da Educação Física e do Diretório Acadêmico. Então, naquela época o fervo era muito grande. Vinha a turma de esquerda e conversava e eu: "Não. Eu fecho com vocês. Eu sou de esquerda". E vinha a turma da direita e eu já tinha tratado isso com todo mundo, que eu tinha que agradar todo mundo para nós ingressarmos na UFRGS. Tanto faz se é da esquerda ou da direita, nossa intenção era ser aceito. Era interessante porque tinha três diretórios que eram da esquerda e três diretórios que eram da direita. Então, conforme a entrada da Educação Física, ia para um lado ou para outro. Conversava com o diretor que então era o Fredolino Taube. Eu dizia para ele: "Olha, nós temos que cuidar por causa da nossa tendência política e coisa". Embora guri e acompanhei, eu era brizolista da época de 1962, da legalidade, aquela coisa toda, mas na hora tive... E muito aconselhado também pelo meu professor de basquete que era advogado também e que dizia: "Faz isso, faz aquilo, cuidado, não faz aquilo". Quando deu o rolo maior, por aconselhamento dele, eu me demiti do Diretório para garantir as coisas, para não precisar ter uma posição política. (BEMVENUTI, 2010, p. 12).

Na sequência, o entrevistado narra que ao assumir a direção do DCE, percebeu o quanto essa atitude poderia repercutir no processo da federalização. Orientado pelos professores da ESEF, havia o interesse que se afastasse do cargo para não evidenciar alguma tendência política por parte da Escola. Ele continua dizendo: "Fizemos essa articulação para dar garantia, porque, realmente, a coisa não foi assim decisiva. Estava sendo estudada e aprovaram. Depois, em meados de 1970, é que a coisa se oficializou" (BEMVENUTI, 2010, p. 14). 
Os silêncios, os cuidados, a tentativa de "neutralidade" política marcou o processo de transição da ESEF, sob o julgo do Estado do Rio Grande do Sul para a União, período tenso que durou aproximadamente um ano, haja visto que o decreto data de outubro de 1969 e a oficialização do processo veio ocorrer em setembro de 1970.

Realmente, depois que a coisa se concretizou ele [Fredolino Taube] me abraçou e disse: "Tu conduziu muito bem a coisa" e eu disse: "Eu conduzi por orientação de vocês. A minha intenção era igual a de vocês. Vamos batalhar para que se federalize" (BEMVENUTI, 2010, p. 17).

O envolvimento de Bemvenuti e sua percepção sobre o processo de federalização representa um olhar específico sobre ele, decorrente, fundamentalmente, de seu envolvimento com o Diretório Acadêmico. Essa percepção, no entanto, não figura de modo claro em muitos dos discentes da turma de 1970. Muitos deles sequer percebiam a importância do movimento que circulava no seu entorno.

[...] naquela época, quem era atinado, estava fazendo um movimento político. Quem não era, estava fazendo o seu curso lá bem desligado do mundo. E aqui, na Educação Física, as pessoas, enquanto grupo, eram alienados. Algumas pessoas individualmente eram mais antenadas e sabiam o que estava acontecendo, o que estava passando. Então, essa alienação nos fazia a falta de informação. Não tínhamos acesso. Chegou um dia e alguém disse: "Olha, a ESEF vai ser da Universidade". Então, éramos comunicados. Sabemos que teve alguma coisa nesse momento (OLIVEIRA, FERREIRA, KROEFF, 2010, p. 21).

Para além dos estudantes, muitos professores da ESEF também tiveram pouco envolvimento e, mesmo conhecimento sobre o processo da federalização. Até mesmo o diretor da Escola afirma que pouco sabia sobre o que estava em andamento. Nas suas palavras: 
Bom, eu vou dizer uma coisa: como a gente não era professor de tempo integral, a gente dava umas aulinhas e desaparecia. Não, não tinha conhecimento de certas coisas e as coisas nem vinham... Não eram publicadas nem vinham ao conhecimento da gente. Por isso eu vou dizer, a Federalização, ela era algo que tinha um rumorzinho sobre a possibilidade da Escola ser federalizada, de fazer parte da Universidade. Mas a gente não sabia quando nem como e aquilo tomou corpo naquela época que o Médici era presidente da República e o Passarinho era Ministro da Educação (TAUBE, 2004, p. 1).

Depoimentos como esses indicam que aqueles que tinham maior conhecimento do processo da federalização ou dele tomavam parte eram aqueles alunos e professores que, de certo modo, possuíam vivência ou consciência política do que acontecia em um país sob a égide do regime militar ${ }^{13}$.

Os depoimentos de ex-dirigentes do Diretório Acadêmico possibilitam essa afirmação. Segundo Gutierrez (2008, p. 4), para os alunos envolvidos com o Diretório, o processo de federalização "foi muito batalhado. Muita gente batalhou, se interessou, se esforçou e conseguiu essa federalização [...] que não tinha verba planejada nem disponível, mas na hora que veio, veio bem. Souza (2008, p. 5), corrobora essa afirmação ao narrar que a luta em defesa da sede própria e da federalização da ESEF era prioritária para o Fizemos essa articulação para dar garantia, porque, realmente, a coisa não foi assim decisiva. Estava:

Mas era prioridade, sempre achamos que era prioridade, essa sede própria, principalmente também, poder nos vincular à União porque achávamos que enquanto estivéssemos sob a égide da Secretaria de Educação, o nosso crescimento técnico seria sempre muito limitado.

\footnotetext{
${ }^{13}$ Sobre esse tema ler: Educação Física escolar e a Ditadura Militar no Brasil (1968-1984): entre a adesão e a resistência (OLIVEIRA, 2003)
} 
A federalização da ESEF integrava um movimento político em voga neste período que associava a Educação Física ao desenvolvimento nacional. Integra o que Oliveira (2003) denomina de um movimento de "renovação da Educação Física" cujo início se dá no final dos anos de 1960 e que envolve: a reforma universitária de 1968 que expande a oferta de vagas nos cursos superiores impulsionando a formação de profissionais; o investimento de governo na formação de quadros em caráter de emergência, a definição de políticas para a área, o incentivo para uma política de publicação e circulação de ideias sobre a Educação Física, o fomento à pesquisa e à pós-graduação. Por outro lado, a corporação dos especialistas fazendo emergir programas municipais e estaduais para a área; a forte influência do esporte sobre as práticas escolares; o debate sobre o estatuto científico da educação Física e a expansão das competições com caráter "formativo": competições intraescolares, Jogos Escolares, Jogos Escolares Brasileiros, Jogos Universitários Brasileiros (OLIVEIRA, 2003). Ou seja, fazia parte de uma política. No caso, de uma política governamental que buscava o "Brasil Grande" sonhado pelos militares e que pode ser apreendido nas palavras de um tenente coronel:

Divulga, promove-se a Educação Física através de cursos, encontros, estágios, campanhas, visando ao nascimento da necessidade inadiável e imprescindível da prática de exercícios físicos em massa, capaz de sublimar-se nos estados de desenvolvimento de nosso povo que os tempos atuais reclamam, o qual é o clímax, é o topo, a conseqüência, a finalidade da Educação Física. Combate-se a malquerença, a maledicência, a crítica destrutiva, que dividem, que desunem e obstam os esforços em ajudar nosso atual governo a construir uma Nação, mais forte, mais acatada e acreditada no conceito das demais Nações; O BRASIL GRANDE (COSTA, 1969 apud OLIVEIRA, 2003).

A noção de que a federalização da ESEF se deu por uma questão de política nacional figura no depoimento de uma servidora da ESEF. Ao narrar sobre o envolvimento dos funcionários da Secretaria afirma que o processo não foi nada fácil ao mesmo tempo que aponta que

Movimento, Porto Alegre, v. 16, n. esp., p. 11-36, 2010. 
"[...] sempre tem aquela história da política, por isso que nós passamos para federal, porque não tinha no Rio Grande do Sul, aí era também a nossa vantagem, é a eterna política" (GIÁCOMO, 2005, p. 3).

Política essa que, para a grande maioria dos discentes da turma de 1970 mostrava-se de forma muito tênue, quase desapercebida. Segundo Bemvenuti, (2010, p. 16) "[...] a maioria da turma não estava nem aí. Eles nem se lembravam que eu havia sido presidente. Era certa alienação. E naquela época foram os anos feios da ditadura, 1968, 1969 e 1970"

Quando percebida, foi de um modo despolitizado cuja consciência do ocorrido aconteceu tempo depois: "Nós vivemos isso, tivemos notícia, não participamos de nada desse processo. Recebíamos só a informação quando as coisas já estavam consumadas. Também ninguém vinha perguntar se nós queríamos ou não" (OLIVEIRA; FERREIRA; KROEFF, 2010, p. 27).

Ou seja, percepção sobre o processo político da federalização da ESEF e sua conexão com o governo militar passou ao largo do sentimento e do pensamento da maioria daqueles que viveram esse processo por dentro. Exceto os integrantes do Diretório Acadêmico, cuja pauta de reivindicações, continha a federalização, a maioria dos discentes não a perceberam, nem no plano político, nem nas alterações decorrentes da sua concretização.

\section{A nOVA EsEF AOS OLHARES DISCENTES}

Sob a perspectiva dos estudantes do período, o processo de federalização, em pouco se fez presente, ou ainda, pouco representou mudanças na estrutura, tanto física quanto organizacional e administrativa da Escola. Talvez isso tenha acontecido em função do pouco tempo que usufruíram da nova ESEF, depois de federalizada. Afinal, concluíram a sua graduação concomitantemente ao referido processo, de modo que as possíveis mudanças que a Escola viria a presenciar, não chegaram a mudar ou influenciar a formação desses professores. 
Nunes e Molina Neto (2005, p. 6) apontam que as mudanças curriculares, como a matrícula por meio de créditos, e não mais seriada, começou a ser utilizada somente para as turmas com ingresso em 1971-1972. Segundo o depoimento do diretor Taube (2004), a mudança para o sistema de créditos veio a alterar o perfil das turmas de estudantes:

[...] também fez com que as turmas se dispersassem ao longo do curso: começou com o negócio das disciplinas. O cara faz lá a disciplina e se desvincula do resto. Ele não faz parte da escola, ele faz aquela disciplina. Quando o cara tirava uma série, ele fazia parte da escola, não é? [...] a disciplina foi feita para facilitar o estudo dos alunos. O cara não tem tempo pra fazer a série, daí a disciplina. Se ele tem tempo, ele faz tudo. [...] e com isto ele (o processo de Federalização) desmanchou aquilo que era antigamente série e tal. Então às vezes eu ficava chateado por causa disso.

Se a mudança acima não foi vivenciada pela turma formada em 1970, algumas outras, foram relatadas. Uma delas foi a alteração no modo através do qual os estudantes ingressavam na ESEF. Vejamos:

[...] antes da federalização era dividido em duas partes: uma teórica, eu tenho até o boletim, com provas de física, química, matemática, etc... E provas práticas dentro da ESEF. Então o vestibular era especificamente dentro da faculdade não se concorria com ninguém a não ser os próprios inscritos daquele vestibular. [...] e essa foi uma das mudanças sentidas pelos alunos com a Federalização, pois após 1970, o vestibular passou a ser "unificado onde todo mundo concorria com todas as faculdades de acordo com a sua opção" (MARCZWSKI, 2011, p.1).

A novidade dos testes práticos para o ingresso no curso demonstrava o novo perfil que estava em construção e que primava pela preocupação com a aptidão física, foco esse que privilegiaria o esporte como seu principal conteúdo. Os testes físicos, portanto, legitimavam um perfil profissional de professor de educação física 
dotado de aptidões esportivas. O Diretório Acadêmico, cuja diretoria tinha alunos da turma de 1970, ao perceberem essa modificação, elaboraram estratégias para dela tirar proveito. Não no sentido de politizar a discussão, mas de angariar fundos. Criaram, assim, um curso de preparação:

[...] para os alunos que queriam aprender ou se preparar para ir ao vestibular, na questão prática. Os colegas davam aulas como natação, atletismo, voleibol, basquete, tudo aquilo que caía nas provas práticas nós fizemos. Se cobrava uma mensalidade e ia pra caixinha. (MARCZWSKI, 2011, p. 4).

Na percepção dos alunos de 1970, a federalização não resultou em muitas alterações, nem mesmo na melhora das instalações da Escola. Essa percepção é bastante distinta daquela expressa pela Direção da Escola, a qual aponta que no período depois de ser incorporada à Universidade, a ESEF passou a receber reformas em sua velha estrutura e também a ganhar novas edificações:

[...] a nossa cancha de tênis era uma porcaria de cancha lá...agora ...aterraram tudo aquilo lá, fizeram canchas de cimento [...] depois da Federalização [...] aí veio verba, fizeram uma boa piscina, aquecida, e construíram um estádio, botaram Tartan na pista, aquela cobertura, tudo isso não existia. Tudo depois da entrada pro governo federal. A mudança para o federal foi muito boa porque em poucos anos a Escola floresceu, ela ficou outra coisa..." (TAUBE apud NUNES; MOLINA NETO, 2005, p. 184).

Vários documentos analisados tais como atas de reuniões e registros oficiais da Escola ${ }^{14}$ contemplam outras informações indicando um grande investimento na edificação de espaços destinados a prática esportiva. Essa meta atendia o investimento governamental no esporte universitário, impulsionado pela Reforma Universitária que instituía a obrigatoriedade da prática esportiva para todos os estudantes do ensino superior. Demanda essa que causava

\footnotetext{
${ }^{14}$ No acervo do CEME há vários projetos e plantas arquitetônicas nas quais se pode perceber as alterações na infra-estrutura da ESEF.
} 
preocupação a UFRGS, pois percebia a urgência em ampliar seu parque esportivo. Em 1973, o Engenheiro Egydio Hervé Filho, então chefe da Divisão de Obras, aponta que, após um minucioso levantamento não havia locais adequados para atendimento de mais de 12 mil alunos e que "[...] nem mesmo a ESEF, recentemente incorporada a UFRGS, dispunha de condições satisfatórias para a execução de seu plano de formação didático-pedagógica (UNIVERSITÁRIOS..., 1973, p. 6 apud CARVALHO, 2010, p. 29).

As melhorias nas condições físicas e materiais da ESEF pósfederalização foram apontadas, também, pela então Secretária da Escola, que em depoimento afirma:

A UFRGS deu muita assistência para nós, porque éramos precários. Então, tanto na aquisição de material didático, do material diário, de atendimento do professor, de atendimento do aluno [...] Então, aquele primeiro ginásio feitos ali" (GIÁCOMO, 2005, p. 4).

Outras alterações pós-federalização identificadas nos estudos de Nunes e Molina Neto (2005), Mazo (2005), Kaminski e Goellner (2010), Carvalho (2010) e identificadas em entrevistas que integram o acervo do CEME tais como Licht (2008), Reis (2010), Cassel (2005) entre outros. No entanto, não foram percebidos nos relatos dos discentes da turma de 1970.

O que eles registram como significativo após a federalização foi a alteração que se deu na cerimônia de formatura que foi realizada, pela primeira vez, do Salão de Atos da Universidade e seguindo o protocolo exigido pela UFRGS (OLIVEIRA; FERREIRA; KROEFF, 2010; BEMVENUTI, 2010; MARCZWSKI, 2011). Em anos anteriores, a referida cerimônia, já havia sido realizada no Theatro São Pedro, Esporte Clube Cruzeiro e Pontifícia Universidade Católica do Rio Grande do Sul (MAZO, 2005) demonstrando certa dificuldade em se estabelecer um lugar fixo para a realização dessa solenidade. Instabilidade essa que acompanhou a ESEF até sua federalização. 
A oficialização da cerimônia de formatura como pertencente à UFRGS gerou nos alunos grande satisfação. Em depoimento, o professor Fredolino Taube rememora a visita do Reitor Eduardo Zaccaro Faraco (1968-1972) às dependências da ESEF e a comunicação que fez aos alunos sobre o ato solene: "[...] o pessoal dava vaia nele antigamente, mas ali, ele entrou e a turma deu uma salva de palmas pra ele e ele ficou abobado com a recepção que ele recebeu dos alunos, a ordem que tinha, aquela coisa lá, todo mundo uniformizado" (TAUBE, 2004, p. 3).

Uma questão apontada nos depoimentos e que gerou desgosto com relação a essa cerimônia foi a impossibilidade dos alunos indicarem seu paraninfo. Diante da ESEF federalizada e sob a égide do governo militar, houve a imposição de que o Ministro da Educação, Jarbas Passarinho, fosse o paraninfo dessa primeira turma a colar grau com título conferido pela UFRGS.

Nós não escolhemos. Nós fomos coagidos a aceitálo como paraninfo da turma. Ele tinha feito uma visita aqui na Universidade e veio aqui, porque nós fizemos uma apresentação do grupo de ginástica aqui para a mulher dele. Tem até as fotos com a mulher dele. Então, a nossa passagem aí é isso. Nós fizemos demonstração de ginástica, o nosso Diretório Acadêmico parece que fez alguma movimentação (OLIVEIRA; FERREIRA; KROEFF, 2010, p. 21).

Os alunos formados em 1970 pouco usufruíram dos benefícios da federalização da Escola. Do pouco tempo que eles foram alunos da ESEF, incorporada a Universidade Federal, as mudanças na cerimônia de colação de grau foram as que eles tiveram tempo hábil de vivenciar. Nos depoimentos produzidos para essa pesquisa apontaram que os benefícios advindos com a federalização foram percebidos e usufruídos apenas pelas turmas que ingressaram na Escola a partir de 1970. No entanto, o sentimento de pertencimento à Universidade emergia como algo que lhes conferia status e dignidade: 
Agora, para nós, na época, enquanto sentimentos, eu acho que foi importante o pertencimento à Universidade, porque isso era um "status". Isso foi o sentimento que nós tivemos: "Bom, agora nós somos da Universidade! (OLIVEIRA; FERREIRA; KROEFF, 2010, p. 21).

E, por preconceito ou não, acredito que por preconceito, quando eu fiz a minha segunda formação, não foi na Universidade Federal. Então, eu já não me senti tão orgulhosa - muito embora tenha saído formada como qualquer outro profissional - mas é uma coisa que eu acho que teria me sentido mais orgulhosa se tivesse me formado na Universidade Federal (OLIVEIRA; FERREIRA; KROEFF, 2010, p. 28).

A turma formada em 1970, por mais que não tenha vivenciado muitas das mudanças decorrentes do processo de federalização, era a turma que estava presente nas dependências da ESEF de então o que, em tese, poderia supor seu maior envolvimento ou mesmo conhecimento sobre esse processo. No entanto, parece não ter sido bem assim.

\section{Considerações Finals}

No ano de 1969 o Instituto de Pesquisas Econômicas e Avançadas (IPEA) encomendou um documento que fundamentou muitas das ações que foram desenvolvidas nas décadas seguintes. Intitulado "Diagnóstico de Educação Física e Desportos no Brasil", este estudo apresentava uma análise quantitativa com ênfase nas condições do desenvolvimento dessas áreas bem como "[...] no planejamento, na otimização de recursos, na eficácia e no controle dos resultados, todos aspectos bem afeitos à tecnocracia" (OLIVEIRA, 2003, p. 109).

Dentre as inúmeras ações dele decorrentes e, mesmo, antecedentes a sua elaboração, o investimento na formação de profissionais de Educação Física foi uma delas. A federalização de algumas Escolas de Educação Física fez parte desse processo uma 
vez que, a partir de 1964, o sistema de ensino brasileiro passou por uma série de transformações. Um de seus objetivos estava direcionado para a formação de mão de obra qualificada para suprir o processo de industrialização em andamento com fortes influências do capital estrangeiro. A Reforma Universitária foi promulgada atendendo, também a esse fim (MOLINA NETO; NUNES, 2005). Baseada no modelo universitário americano, visava o aumento da eficiência e da produtividade das Universidades, tendo como um dos objetivos, segundo Freitag apud Betti, p. 101, "[...] atender a demanda de um mercado de trabalho sofisticado, como decorrência do modelo econômico adotado pós-64".

No contexto do Brasil Grande, protagonizado pelos militares, a Educação Física passou a ser reconhecida como uma área relevante pois mantinha estreita ligação com o desenvolvimento da aptidão física e do esporte. A primeira, porque era considerada importante para a capacidade produtiva da nação (da classe trabalhadora) e o segundo, "pela contribuição que traria para afirmar o país no concerto das nações desenvolvidas (Brasil potência) e pela sua contribuição para a primeira, ou seja, para a aptidão física da população" (BRACHT, 1999, p. 87).

A federalização da ESEF fez parte dessa política sendo vivenciada de modo distinto pelos integrantes de sua comunidade. Enquanto alguns defendiam sua concretização e agiam em sua defesa, para muitos nem sequer era visibilizada. A turma de 1970, aqui eleita para protagonizar a cena sobre a percepção de como se deu o processo de federalização da Escola, é exemplar para essa afirmação. Os alunos envolvidos com o Diretório Acadêmico estavam cientes e envolvidos nesse processo. Fazia parte da pauta de suas reivindicações políticas. Mas a grande maioria, em sua letargia política, sequer supunha o que acontecia na Escola e, talvez, fora dela.

A nova ESEF que se erguia diante de seus olhos em consequências da federalização foi vivenciada de modo muito peculiar pelos integrantes da turma graduada em 1970: por dentro do processo, mas, em certa medida, muito afastada dele. 
ESEF 70 Years: The process of federalization under the student's view

Abstract: This paper analyzes the process of federalization of the School of Physical Education of the Federal University of Rio Grande do Sul under the eyes of students who graduated in 1970 in the first group formed under the federal system of education. Based on the theoretical support of Cultural History, we reviewed issues related to political involvement of students in this process and aspects of the structure and functioning of the school as a whole. To this end, we resorted to Oral History, interviewing students and teachers of the period, and analyzed sources of various kinds such as documents, minutes of meetings, books, newspaper reports, photographs, and more. Based on the analysis, we noted that this class has experienced federalization in a very peculiar way: within the process, but to some extent, far away from it.

Keywords: History of the Twentieth Century: Brazil. Policy. Physical education. Students. Universities.

\section{ESEF 70 Años: el proceso de federalización bajo la mirada discente \\ Resumen: Este artículo analiza el proceso de federalización de la Escuela de Educación Física de la Universidad Federal de Rio Grande do Sul bajo la mirada de los discentes que se graduaron en 1970 en la primera promoción formada bajo el régimen federal de enseñanza. Fundamentada con el aporte teórico de la Historia Cultural analizamos aspectos relacionados al compromiso político de los alumnos en ese proceso así como también aspectos relacionados a la estructura y funcionamiento de la Escuela como un todo. Para esto, recorremos la Historia Oral entrevistando discentes y docentes del periodo así como también analizamos fuentes de diversa naturaleza tales como documentos, actas de reuniones, libros, reportajes de periódicos, fotografías, entre otras. Del análisis realizado aprendemos que esta promoción vivió la federalización de modo muy particular: por dentro del proceso, pero, en cierta medida, muy alejada de él.}

Palabras clave: Historia del siglo XX: Brasil. Política. Educación física. Estudiantes. Universidades. 


\section{REFERÊNCIAS}

ALBERTI, Verena. História oral e a experiência do CPDOC. Rio de Janeiro: Centro de Pesquisa e Documentação de História Contemporânea do Brasil, 1989.

BEMVENUTI, Edson. Depoimento de Edson Bemvenutti. Porto Alegre: ESEF/ UFRGS, 2010. 15 f. (Projeto Garimpando Memórias) ${ }^{15}$.

BETTI, Mauro. Educação física e sociedade. São Paulo: Movimento, 1991.

BRACHT, Valter. A constituição das teorias pedagógicas da educação física. Caderno CEDES, Campinas, v.19, n.48, p. 69-88, 1999. Disponível em: < http:// www.scielo.br/scielo.php?script=sci_arttext\&pid=S0101>. Acesso em: 05 mar. 2011.

CARVAlHO, Marco A. A. de. Centro Natatório da Escola de Educação Física da UFRGS: espaço de transformações. Trabalho de Conclusão de Curso (Graduação em Educação Física). ESEF/UFRGS, Porto Alegre, 2010. 71 f. Disponível em: http://www.bibliotecadigital.ufrgs.br/da.php? nrb=000750125\&loc= 2010\&l=bcc3a33d9b93bc7f. Acesso em: 20 dez. 2010.

CASSEL, Mário C. Depoimento de Mário César Cassel. Porto Alegre: ESEF/ UFRGS, 2005. 25 f. (Projeto Garimpando Memórias). Disponível em: <http:// www.bibliotecadigital.ufrgs.br/da.php? n rb $=000734874 \&$ loc $=$ 2010\&l=65e0b9eb29d9ef7f>. Acesso em: $20 \mathrm{dez}$. 2010.

CASTELLANI FILHO, L. Educação física no Brasil: a história que não se conta. Campinas: Papirus, 1988.

ECHART, Olga Valéria Kroeff. Depoimento de Olga Valéria Kroeff Echart. Porto Alegre: ESEF/UFRGS, 2004. 31 f. (Projeto Garimpando Memórias). Disponível em: <http://www.bibliotecadigital.ufrgs.br/da.php? nrb=000728888\&loc= 2010\&l=d0bf041c32e2126e $>$. Acesso em: 15 fev. 2011.

FALCON, F. J. História cultural: uma visão sobre a sociedade e a cultura. Rio de Janeiro: Campos, 2002.

FERREIRA, Marieta de M.; AMADO, Janaína (Org). Usos e abusos da história oral. Rio de Janeiro: Fundação Getúlio Vargas, 1996.

FERREIRA NETO, Amarilio. A pedagogia do Exército na escola: a educação física brasileira (1880-1950). Aracruz: FACHA, 1999.

GIÁCOMO, Maria do Carmo. Depoimento de Maria do Carmo Giácomo. Porto Alegre: ESEF/UFRGS, 2005. 13 f. (Projeto Garimpando Memórias). Disponível em: < http://www.bibliotecadigital.ufrgs.br/da.php? nrb $=000729087 \&$ loc $=$ 2010\&l=d46db37a569e7f6f $>$. Acesso em: 02 mar. 2011.

${ }^{15}$ Disponível no Acervo do Centro de Memória do Esporte da ESEF/UFRGS. 
GUTIERREZ, Washington. Depoimento de Washington Gutierrez. Porto Alegre: ESEF/UFRGS, 2008. 24 f. (Projeto Garimpando Memórias). Disponível em: < http:// www. bibliotecadigital.ufrgs.br/da.php? nrb $=000752340 \& \mid 0 c=2010 \& \mathrm{I}=$ 2aa8d953d40261ec>. Acesso em: 20 fev. 2011.

GUTIERREZ, Washington. Histórico. Porto Alegre, 1971. Disponível em: <http:// www.esef.ufrgs.br/historia.htm>. Acesso em: 20 dez. 2010.

KAMINSKI, Leon Frederico; GOELLNER, Silvana Vilodre. Corpo discente em movimento: reivindicações estudantis na Escola Superior de Educação Física do Rio Grande do Sul (1957-19640).Motriz, Rio Claro, v. 16, n. 4, p. 984-994, out./dez. 2010.

LICHT, Henrique Felippe Bonnet. Depoimento de Henrique Felippe Bonnet Licht III. Porto Alegre: ESEF/UFRGS, 2005. 18 f. (Projeto Garimpando Memórias). Disponível em: < http://www.bibliotecadigital.ufrgs.br/da.php?nrb=000729778\&loc= 2010\&l=322af5517974918b>. Acesso em: 27 fev. 2011.

MARCZWSKI, Mauro. Depoimento de Mauro Marczwski. Porto Alegre: ESEF/ UFRGS, 2011, 12 f. (Projeto Garimpando Memórias) ${ }^{16}$.

MAZO, Janice Z. Memórias da Escola Superior de Educação Física da Universidade Federal do Rio Grande do Sul (ESEG/UFRGS): um estudo do período de sua fundação até a federalização (1939-1969). Movimento, Porto Alegre, v. 11, n. 1, p. 143167, jan./abr. 2005.

MEIHY, J.C.S.B. Manual de história oral. 2. ed. São Paulo: Loyola, 1998.

NEGRINE, A. (Org.). Perfil do Curso de Mestrado em Ciências do Movimento Humano desde sua implantação 1989-1995: Universidade Federal do Rio Grande do Sul. Escola de Educação Física. Porto Alegre, maio de 1996.

NUNES, Cássio F. T.; MOLINA NETO, Vicente. O processo de federalização da ESEF/UFRGS sob a perspectiva dos professores: o estudo de caso. Movimento, Porto Alegre, v. 11, n. 2, p. 167-190, maio/ago. 2005.

OLIVEIRA, Vera Lúcia da Silva; FERREIRA, Vera Maria; KROEFF, Maria Alice Garcia. Depoimento de Vera Lúcia da Silva Oliveira, Vera Maria Ferreira e Maria Alice Garcia Kroeff. Porto Alegre: ESEF/UFRGS, 2010, 42f. (Projeto Garimpando Memórias) ${ }^{17}$.

OLIVEIRA, Marcus A. T. de. Educação física escolar e a ditadura militar no Brasil (1968-1984): entre a adesão e a resistência. Bragança Paulista: EDUSF, 2003.

PESAVENTO, S. J. História \& história cultural. Belo Horizonte: Autêntica, 2003.

16,17Disponível no Acervo do Centro de Memória do Esporte da ESEF/UFRGS. 
REIS, Jayme Werner dos. Depoimento de Jayme Werner dos Reis II. Porto Alegre: ESEF/UFRGS, 2010. 31 f. (Projeto Garimpando Memórias). Disponível em: < http://www. bibliotecadigital. ufrgs.br/da.php? $\mathrm{nrb}=000751091 \& \mathrm{loc}=2010 \& \mathrm{l}=$ e738676ed0385a86>. Acesso em: 02 mar. 2011.

ROUSSO, Henry. A memória não é mais o que era. In: FERREIRA, Marieta de M.; AMADO, Janaína. (Org.). Usos \& Abusos da História Oral. Rio de Janeiro: Fundação Getúlio Vargas, 1996.

SILVA, Vinicius Ruas da. Depoimento de Vinicius Ruas da Silva. Porto Alegre: ESEF/UFRGS, 2010. 10 f. (Projeto Garimpando Memórias). Disponível em: < http:// www. bibliotecadigital.ufrgs.br/da.php? $\mathrm{nrb}=000736881 \& \mathrm{loc}=2010 \& \mathrm{l}=$ ad089d231d1724d6>. Acesso em: 05 mar. 2011.

SOUZA, Walter Frederico de. Depoimento de Walter Frederico de Souza I. Porto Alegre: ESEF/UFRGS, 2005. 18 f. (Projeto Garimpando Memórias). Disponível em: <http://www.bibliotecadigital.ufrgs.br/da.php?nrb=000729641\&loc $=2010 \& \mathrm{I}=$ 614b3b253f9d0568>. Acesso em: 05 mar. 2011.

SOUZA, Walter Frederico de. Depoimento de Walter Frederico de Souza II. Porto Alegre: ESEF/UFRGS, 2008. 16 f. (Projeto Garimpando Memórias). Disponível em: <http://www.bibliotecadigital.ufrgs.br/da.php?nrb=000729772\&loc $=2010 \& \mathrm{l}=$ fc1193c6075f2b49>. Acesso em: 05 mar. 2011.

TAUBE, Fredolino Adalberto Ricardo. Depoimento de Fredolino Adalberto Ricardo Taube III. Porto Alegre: ESEF/UFRGS, 2004. 23 f. (Projeto Garimpando Memórias). Disponível em: < http://www.bibliotecadigital.ufrgs.br/da.php?nrb= $000728726 \& l o c=2010 \& \mathrm{l}=e 3 b 4 d 7 c 9083 c 6501>$. Acesso em: 10 jan. 2011.

THOMPSON, Paul. A voz do passado: história oral. Rio de Janeiro: Paz e Terra, 1992. 
